\title{
MESENCEPHALIC TUBERCULOUS ABCESS IN A PATIENT WITH AIDS
}

\author{
Stélio da Conceição Araújo-Filho', Laerte Maia', Harley Brito da Silva', \\ João Paulo Cavalcante de Almeida ${ }^{2}$, Lucas Alverne Freitas de Albuquerque ${ }^{2}$
}

The review of recent published papers demonstrates that a considerable amount of brain abscesses has been associated to opportunist microorganism, such as Toxoplasma ghondii, Aspergillus spp., Nocardia spp., Mycobacteria spp., Criptococcus neoformans and Listeria monocytogenes. Those data reflects the enlarging number of imunocompromised patients (AIDS, post-transplantation) as an important risk group for this condition'. The high spread of HIV infection, besides raising tuberculosis prevalence, is an important cause of the considerable proportion of extrapulmonary, disseminated, drug resistant and multiinfection tuberculosis (TB) nowadays ${ }^{2}$. When there is association between HIV and TB infections, central nervous system (CNS) is affected in $5-20 \%$ of the cases $^{3}$. The main clinical presentation is TB meningitis in those patients.

Focal TB lesions are rare and may present as tuberculomas and, still more infrequent, as brain abcesses, rare conditions of considerable neurosurgical interest ${ }^{4,5}$.

We report one such case.

\section{CASE}

A 35 years-old woman was admitted in our center after being transferred by another hospital presenting a history of generalized tonic-clonic seizures episodes and a persistent severe holocranial headache. The MRI (Fig 1) realized in the other hospital showed an intracranial expansive mass localized in the right thalamus mesencephalic region.

The neurological examination at admission demonstrated a conscient patient, with right palpebral ptosis and left hemiparesia. She also had a history of multiple sexual partners in the last years. Her laboratorial examination revealed leucopenia (4400 cell $/ \mathrm{mm}^{3}$ ) and lymphopenia $\left(616 \mathrm{cell} / \mathrm{mm}^{3}\right)$. Chest radiography was normal. Considering the possibility of HIV infection, antiHIV 1 and 2 tests were realized, both were negative at time of testing. Presenting deterioration of consciousness level, the patient was transferred to the intensive care unit of our hospital. CT scan (Fig 2) was performed and confirmed the previous MRI finding, showing important brain edema and mass effect.

Stereotatic drainage of the lesion was performed, draining
$8 \mathrm{~mL}$ of pus. Pathological examination of the material revealed HIV, Mycobacterium tuberculosis and Toxoplasma ghondii. Then the patient started treatment with rifampicine, isoniazide, pirazinamide (RIP) for tuberculosis; and sulfadiazine, pirimetamine

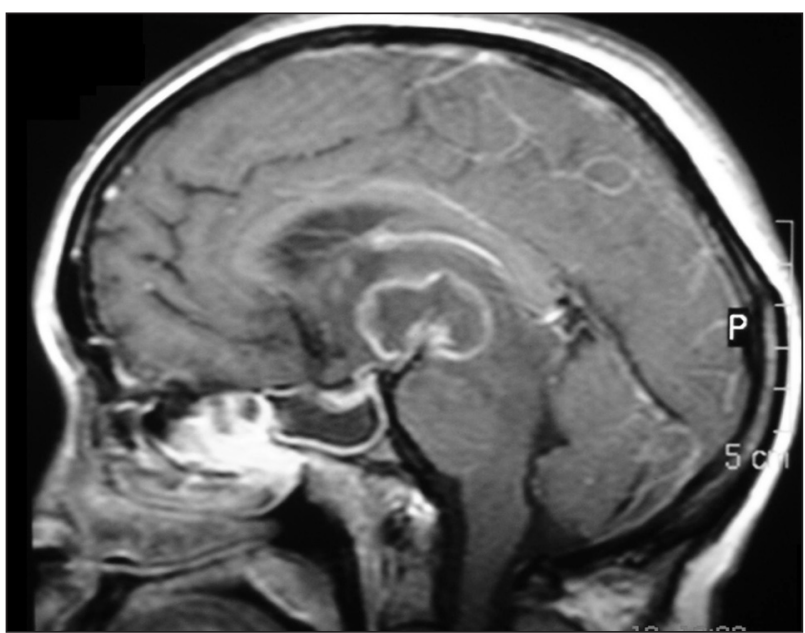

Fig 1. Sagital T-1 weighted image demonstrates the right thalamusmesencephalic lesion.

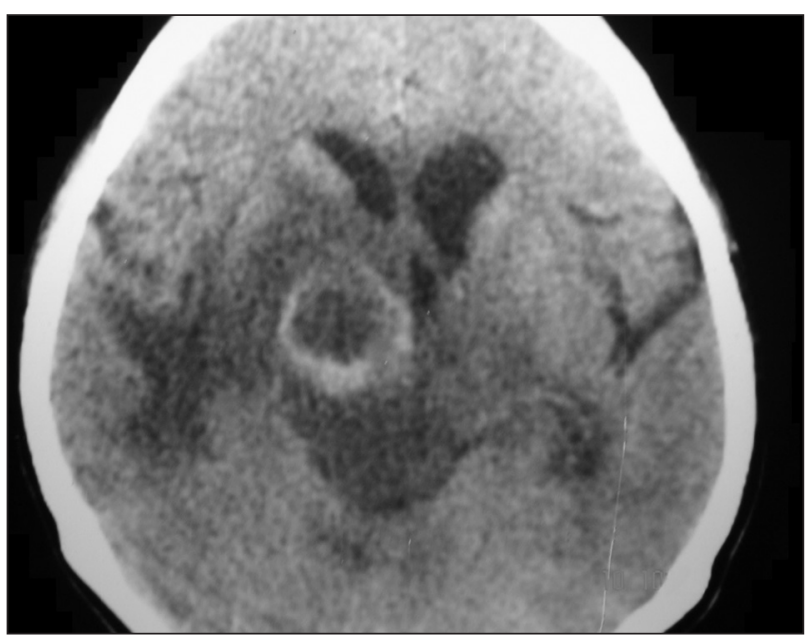

Fig 2. Contrast-enhanced computed tomography scanning demonstrates a single lesion in the right thalamus-mesencephalic region.

\section{ABSCESSO MESENCEFÁLICO TUBERCULOSO EM PACIENTE COM AIDS}

Hospital Batista Memorial, Fortaleza CE, Brazil: ${ }^{M} \mathrm{MD}$, Neurosurgeon; ${ }^{2}$ Medical student at Universidade Federal do Ceará.

Received 25 October 2007, received in final form 29 January 2008. Accepted 3 March 2008.

Dr. João Paulo Cavalcante de Almeida - Rua Paulo Morais 130 - 60175-175 Fortaleza CE - Brasil. E-mail: jpaulocavalcante@yahoo.com.br 
and folic acid for toxoplasmosis. Corticoid therapy was also utilized in the first days of the RIP treatment. The clinical condition of the patient deteriorated and she presented pulmonary infection and respiratory failure. The patient died seven days after admission.

\section{DISCUSSION}

Before the AIDS era, Whitener reviewed from 1886 to 1978 only 17 cases with etiological diagnosis, and established diagnosis criteria of cerebral tuberculous abscess ${ }^{6}$. Vidal et al. ${ }^{12}$, in accordance with Whitener criteria, reviewed the literature about tuberculous abscesses in HIV infected patients. From 1981 to 2003, only 12 cases were found: three in the USA, three in Spain, one in France and five in Brazil $^{2}$. Three of the cases died: one for toxoplasmosis encephalitis, one for post surgical drainage hematoma and one for gastrointestinal hemorrhage associated to cryptococcal meningitis. Eight patients also presented toxoplasmosis at time of diagnosis.

Focal lesions due to brain tuberculosis have two histopathologic aspects of presentation: tuberculoma and abcess. Abscesses are usually single, larger and grow more rapidly than the tuberculomas ${ }^{7}$. Tuberculous abscesses, differently of tuberculomas, have vascular granulation tissue with inflammatory cells similar to pyogenic abscesses. The internal wall of a tuberculous abscess is necrotic while the external surface is fibrous, associated with an inflammatory reaction ${ }^{3}$. The definitive diagnosis of TB brain abscess depends on the following criteria: macroscopic evidence of pus in the abscess cavity, microscopic evidence of acute inflammatory alterations in the abscess walls, and the presence of $M$. tuberculosis or growth on culture $^{6}$. There are other cases of TB brain abcess published, but those do not present such criteria.

Tuberculous brain abscess is usually a subacute illness and the most frequent clinical manifestations are focal signs, headache, fever, seizures and consciousness alterations. The localization of the lesion is essential for determination of the symptoms ${ }^{8}$. There is not a specific site of commitment, but the lesion usually presents in the supratentorial compartment ${ }^{8}$.

Tomographic alterations of the tuberculous abscesses are unspecific for diagnosis in immunodepressed patients. However, there are several imaging characteristics suggestive of CNS tuberculous abscess. Solitary, multiloculated ringenhancing lesions associated with mass effect and edema should raise the clinical possibility of tuberculous abscess.

The differential diagnosis of tuberculous abscesses is wide, including toxoplasmic encephalitis (the most fre- quent cause of intracranial mass in AIDS patients), pyogenic brain abcess and CNS primary lymphoma.

In AIDS patients, the presence of intracranial mass allows empirical treatment for cerebral toxoplasmosis. Failure to respond to therapy dictates the need for a diagnostic stereotactic biopsy. Although it may be considered earlier in the presence of a single lesion demonstrated by MRI with negative serology for $T$. gondii or in cases of brain herniation ${ }^{4}$.

Surgical excision and antituberculous treatment are the mainstay in the management of these uncommon lesions $^{6}$. The surgical treatment may be based on the surgical excision of the lesion or stereotatic aspiration of the abscess. Tyson et al. strongly denounced aspiration and suggested that surgical excision should be considered the treatment of choice 9 . However, tuberculous abscesses have been successfully aspirated by some ${ }^{10}$. Stereotatic aspiration is considered the primary modality of treatment for TB abscesses located in deep locations for our team and other authors ${ }^{11}$.It represents a minimally invasive therapeutic and diagnostic approach for such lesions, presenting effective results and the advantage to do not need the classical large craniectomies.

Antituberculous drug treatment and regular followup is required in these patients, as there is a possibility of reaccumulation during the treatment.

We consider that the poor outcome of our patient is associated to the volume of the mesencephalic lesion presented, association of multiple infectious agents and delay in medical assistance until the patient arrived in our center.

\section{REFERENCES}

1. Sims L, Lim M, Harsh GR. Review of brain abscesses. Oper Tech Neurosurg 2005;7:176-181.

2. Vidal JE, Oliveira ACP, Bonasser Filho F, et al. Tuberculous brain abscess in AIDS patients: report of three cases and literature review. Int J Infect Dis 2005;9:201-207.

3. Mohanty A, Venkatarama SK, Vasudev MK, Khanna N, Anandh B. Role of stereotactic aspiration in the management of tuberculous brain abscess. Surg Neurol 1999;51:443-447.

4. Vidal JE, Cimerman S, Silva PR, Sztajnbok J, Coelho JF, Lins DL. Tuberculous brain abscess in a patient with AIDS: case report and literature review. Rev Inst Med Trop S Paulo 2003;45:111-114.

5. Sepkowitz KA, Raffalli J, Riley L, Kiehn TE, Armstrong D. Tuberculosis in the AIDS era. Clin Microbiol Rev 1995;8:180-199.

6. Whitener DR. Tuberculous brain abscess: report of a case and review of the literature. Arch Neurol 1978;35:148 -155.

7. Yang PJ, Reger KM, Seeger JF, Carmody RF, Iacono RP. Brain abscess: an atypical CT appereance of CNS tuberculosis. Am J Neuroradiol 1987;8:919-920.

8. Mohammedi I, Veber B, Gacht B, Wolff M, Vachon F. [Tuberculous cerebellar abscess in na HIV-infected patien.] Réan Urg 1995;4:317-319. (French)

9. Tyson G, Newman P, Strachan WE. Tuberculous brain abscess. Surg Neurol 1978;10:323-325.

10. Rajsekhar V, Chandy M. CT-guided stereotactic surgery in the management of intracranial tuberculomas. Br J Neurosurg 1993;7:665-671.

11. Mohanty A, Santosh V, Anandh B, et al. Diagnostic efficacy of stereotactic biopsies in intracranial tuberculomas. Surg Neurol 1999;52:252-257. 